\title{
Right ventricular-pulmonary arterial coupling in patients after repair of tetralogy of Fallot
}

\author{
Heiner Latus, MD, ${ }^{\mathrm{a}}$ Wolfhard Binder, MD, ${ }^{\mathrm{b}}$ Gunter Kerst, MD, ${ }^{\mathrm{a}}$ Michael Hofbeck, MD, \\ Ludger Sieverding, MD, ${ }^{\mathrm{b}}$ and Christian Apitz, MD ${ }^{\mathrm{a}}$
}

\begin{abstract}
Objective: Right ventricular-pulmonary arterial coupling is an important determinant in the development of right ventricular failure. The purpose of our study was to assess right ventricular-pulmonary arterial coupling in children and adolescents with dilatation of the right ventricle after repair of tetralogy of Fallot.
\end{abstract}

\begin{abstract}
Methods: Right ventricular-pulmonary arterial coupling was quantified as the ratio of pulmonary arterial elastance (an index of arterial load) and right ventricular end-systolic elastance (an index of contractility) using pressure-volume loops with conductance catheters at the baseline level and during dobutamine infusion.
\end{abstract}

Results: A total of 24 patients (mean age, $16.7 \pm 7.0$ years) after tetralogy of Fallot repair were enrolled in the present study. End-systolic elastance showed an appropriate increase under inotropic stimulation from $0.24 \pm$ 0.18 to $0.47 \pm 0.39 \mathrm{~mm} \mathrm{Hg} / \mathrm{mL} / \mathrm{m}^{2}(P<.01)$. Simultaneously, the arterial elastance increased from $0.50 \pm 0.28$ to $0.72 \pm 0.48 \mathrm{~mm} \mathrm{Hg} / \mathrm{mL} / \mathrm{m}^{2}(P<.01)$. Right ventricular-pulmonary arterial coupling was impaired at rest and did not improve significantly under dobutamine stress in the entire study population (arterial elastance/endsystolic elastance decreased from $3.0 \pm 2.8$ to $2.7 \pm 3.1 ; P=.70$ ). Patients with transannular patch repair $(\mathrm{n}=11)$ showed significant uncoupling in response to dobutamine (arterial elastance/end-systolic elastance increased from $2.0 \pm 0.8$ to $3.7 \pm 4.1$ ), and coupling even improved with dobutamine in patients who had undergone a transatrial approach (arterial elastance/end-systolic elastance decreased from $1.6 \pm 1.0$ to $0.9 \pm 0.6$; $P=.04)$.

Conclusions: Our study demonstrated that right ventricular-pulmonary arterial coupling is impaired in patients with tetralogy of Fallot and is mainly affected by the surgical strategy used at the primary repair. These results elucidate the emerging role of ventricular-arterial interactions as a contributing mechanism for deterioration in right ventricular performance and impaired response to inotropic drugs in patients with tetralogy of Fallot. (J Thorac Cardiovasc Surg 2013;146:1366-72)

Patients after repair of tetralogy of Fallot (TOF) frequently evolve dilatation of the right ventricle, which can lead to progressive right ventricular (RV) failure, during long-term follow-up. ${ }^{1,2}$ Previous studies of this issue have primarily focused on the assessment of RV dimensions and RV function. However, these parameters can only provide limited insight into the complex mechanisms of $\mathrm{RV}$ adaptation to chronic volume overload. ${ }^{1-3}$ The right ventricle does not undergo these pathophysiologic changes alone; rather, it is coupled to a highly compliant lowpressure pulmonary arterial (PA) system. Therefore, RV

\footnotetext{
From the Pediatric Heart Center, ${ }^{a}$ Justus-Liebig University Clinic, Giessen, Germany; and Division of Pediatric Cardiology, ${ }^{\mathrm{b}}$ University Children's Hospital, Tuebingen, Germany.

This study was supported by the Fördergemeinschaft Deutsche Kinderherzzentren, Bonn, Germany.

Disclosures: Authors have nothing to disclose with regard to commercial support. Received for publication Oct 31, 2012; revisions received Jan 26, 2013; accepted for publication Feb 13, 2013; available ahead of print March 18, 2013.

Address for reprints: Christian Apitz, MD, Pediatric Heart Center, Justus-LiebigUniversity of Giessen, Feulgenstr 12, Giessen D-35392, Germany (E-mail: christian.apitz@paediat.med.uni-giessen.de).

0022-5223/\$36.00

Copyright (c) 2013 by The American Association for Thoracic Surgery

http://dx.doi.org/10.1016/j.jtcvs.2013.02.039
}

chamber and myocardial adaptation cannot be regarded independently from the PA system.

By defining the ventricle and the arterial system as 2 elastic chambers, Sunagawa and colleagues ${ }^{4}$ analyzed the ventricular-arterial interactions using the ventricular pressure-volume relationship. Within this framework, the effective pulmonary arterial elastance (Ea) is defined as the ratio of end-systolic pressure divided by the stroke volume and incorporates all elements of total ventricular afterload, including peripheral resistance, arterial compliance, and characteristic impedance. In contrast, ventricular end-systolic elastance (Ees) describes a load-independent parameter of myocardial contractility and is typically determined by invasive measurements with conductance catheters under various loading conditions. The ventricular-arterial coupling is estimated from the Ea/Ees ratio. ${ }^{4-6}$

It has been demonstrated that normal RV functional adaptation to afterload is associated with maintenance of an $\mathrm{Ea} / \mathrm{Ees}$ ratio of about $0.5,{ }^{7-10}$ allowing for flow output at a minimal amount of energy cost, and optimal right ventricular-pulmonary arterial (RV-PA) coupling $($ ratio $=1)$ occurs when the ventricle and arterial system have equal elastances, thereby maximizing energy transfer and stroke work. 

Abbreviations and Acronyms
$\mathrm{CMR}=$ cardiovascular magnetic resonance imaging
$\mathrm{Ea}=$ pulmonary arterial elastance
Ees $=$ end-systolic elastance
$\mathrm{PA}=$ pulmonary arterial
$\mathrm{PR}=$ pulmonary regurgitation
$\mathrm{RV} \quad=$ right ventricular
RVOT $=$ right ventricular outflow tract
$\mathrm{RV}-\mathrm{PA}=$ right ventricular-pulmonary arterial
TAP $=$ transannular patch
$\mathrm{TOF}=$ tetralogy of Fallot

An unfavorable coupling between the right ventricle and pulmonary vascular system with inefficient mechanical work production occurs when the Ea/Ees ratio increases. The uncoupling between the vascular and ventricular properties is an important determinant in the development of RV failure and has recently been reported in pulmonary hypertension. ${ }^{10}$

Accordingly, using a conductance catheter technique, we used this coupling concept in patients with repaired TOF and RV dilatation to achieve a more comprehensive understanding of the matching between RV performance and PA load and to evaluate the role of the PA system at rest and under inotropic stimulation with dobutamine. We specifically sought to determine whether the surgical strategy at primary repair has any effect on RV-PA coupling.

\section{METHODS \\ Study Population}

Participation in the present study was offered to all patients with repaired TOF who were scheduled for elective cardiac catheterization as a part of their assessment of postoperative hemodynamics to decide whether pulmonary valve replacement was required. The patients who had evidence of a residual ventricular septal defect, significant RV outflow tract (RVOT) obstruction, or any abnormal source of pulmonary blood flow were excluded from the present study. All patients or parents of the patients gave written informed consent to a protocol approved by the local ethics committee.

\section{Cardiovascular Magnetic Resonance Imaging}

Cardiovascular magnetic resonance imaging (CMR) studies were performed on a 1.5-T magnetic resonance system (Magnetom Sonata; Siemens Healthcare, Erlangen, Germany) with a maximal gradient strength of $40 \mathrm{mT} / \mathrm{m}$ and a maximal slew rate of $200 \mathrm{mT} / \mathrm{m} / \mathrm{ms}$. The images were acquired with two 6-element phased array coils. No sedation was applied. The ventricular volume and function were assessed using an electrocardiogram-gated steady-state free precession cine magnetic resonance pulse sequence during breath-holding periods. We used a stack of 10 to 12 slices, with a 25 -phase/cardiac cycle at an 8- to 10-mm slice thickness in short-axis planes. The end-diastolic (maximal) and end-systolic (minimal) volumes, stroke volumes, and ejection fractions for the right and left ventricles were calculated using dedicated software (Argus;
Siemens, Erlangen, Germany) after the RV and left ventricular endocardial borders were traced manually at end-systole and end-diastole. All parameters were adjusted to the body surface area. Phase contrast analysis of forward and reverse flow in the pulmonary artery was achieved using a retrospectively gated gradient echo sequence during free breathing (slice thickness 5-6 mm, 26-30 phases per cardiac cycle). The imaging plane was located at the midpoint of the main pulmonary artery and prescribed perpendicular to the vessel using the double oblique technique. In all cases, the encoding velocity was adjusted to avoid aliasing. The pulmonary regurgitant fraction was calculated as a percentage of the pulmonary regurgitant volume divided by the pulmonary forward volume. The pulmonary regurgitant volume was defined as the total reverse flow indexed for the body surface area.

\section{Cardiac Catheterization}

To assess the intrinsic myocardial function of the right ventricle, we used pressure-volume loop analysis and the conductance catheter technique. All studies were performed with the patients under general anesthesia, with the patients intubated and ventilated according to our usual protocol. The conductance study, including the dobutamine stress testing, was started after the hemodynamic part of the right-side and left-side heart catheterization was completed. The principles of the conductance catheter technique for estimating the ventricular volume have been previously described in detail for both ventricles. ${ }^{11-14}$

Functional assessment of the right ventricle was performed using the CD Leycom cardiac function laboratory 512 hardware, software package, version 3.8 (2008) and conductance catheters 71083-PN and 41063-PN (CD Leycom, Zoetermeer, The Netherlands). The conductance catheter with the integrated manometer was placed under fluoroscopic guidance in the apex of the right ventricle. A temporary reduction in ventricular volume (preload reduction) was induced by balloon occlusion of the inferior caval vein. Load-independent indexes of RV function were derived at the baseline level and after 10 minutes of dobutamine infusion, with a maximal dosage of $10 \mu \mathrm{g} / \mathrm{kg} / \mathrm{min}$. The dobutamine infusion was decreased or stopped when the heart rate or systolic pressure increased more than $100 \%$ or when significant rhythm disturbances occurred. Recordings were made during at least 2 maneuvers at each state (baseline and dobutamine) in each subject. If ectopy occurred during the preload reduction, the recording was repeated to obtain at least 2 acceptable measurements. All the measurements were performed during short periods of suspended ventilation at end expiration. Cardiac output was measured using the thermodilution method. Residual RVOT obstruction was calculated as the systolic pressure gradient between the right ventricle and main pulmonary artery. The indexed pulmonary vascular resistance was calculated as the pressure difference between mean pulmonary artery pressure and the mean left atrial pressure divided by the cardiac index. RV systolic and diastolic function were determined by the end-systolic and end-diastolic RV pressure, by the slope of the Ees and end-diastolic pressure-volume relation, and by the maximal and minimal rate of pressure change in the ventricle. The effective pulmonary Ea was calculated as the ratio of endsystolic pressure to stroke volume (indexed for the body surface area; Figure 1). The Ea/Ees ratio was used as an index of RV-PA coupling.

\section{Statistical Analysis}

All continuous variables were tested for normality using the Kolmogorov-Smirnov test. The results are presented as the mean \pm standard deviation. Comparisons of the baseline and dobutamine data were performed using the $t$ test for paired data. An unpaired, nonparametric Mann-Whitney $U$ test was used to compare the patients who underwent a transatrial/transpulmonary approach and those with insertion of a transannular patch (TAP) at the primary repair. The categorical variables were analyzed using Fisher's exact test. Analysis was performed using the GraphPad statistical software package, version 3.0 (GraphPad, San Diego, Calif). $P<.05$ was considered statistically significant. 

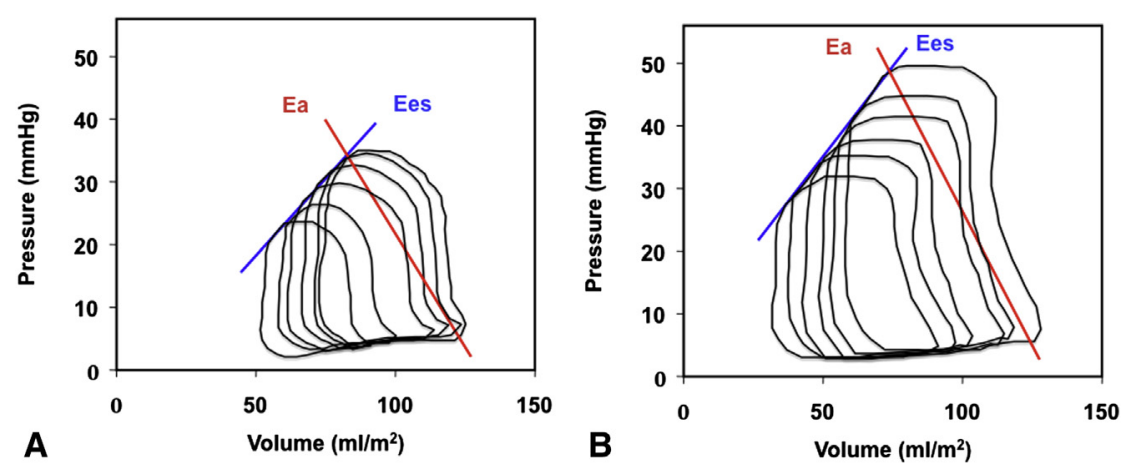

FIGURE 1. Group of pressure-volume loops during preload reduction maneuvers at (A) baseline and (B) dobutamine infusion. The blue line represents the end-systolic pressure volume relation (end-systolic elastance [Ees]) as a parameter of right ventricular contractility; the red line, the slope of the relation connecting the end-systolic and end-diastolic pressure-volume points in the pressure-volume loop that represents the effective pulmonary arterial elastance $(E a)$.

\section{RESULTS}

\section{Study Population and Clinical Findings}

A total of 24 patients with repaired TOF (mean age, 16.7 \pm 7.0 years; mean weight, $53 \pm 25 \mathrm{~kg} ; 9$ females) fulfilled the entry criteria and were enrolled in the present study. The age at repair was $2.3 \pm 3.8$ years, and the mean interval between repair and the present study was $14.5 \pm 5.0$ years. The surgical strategy at primary repair included TAP implantation (11 patients, 46\%), RVOT patch (4 patients, $16 \%$ ), a transatrial/transpulmonary approach (6 patients, $25 \%$ ), and insertion of a RV-PA conduit (3 patients, $13 \%)$. Six patients $(25 \%)$ had undergone initial systemicto-pulmonary shunt procedures (3 with a WaterstonCooley shunt and 3 with a Blalock-Taussig shunt) preceding the corrective surgery. Three patients $(13 \%)$ were in New York Heart Association class 2, the remaining in class 1. The mean brain natriuretic peptide level was $32 \pm 23$ $\mathrm{pg} / \mathrm{mL}$, and the mean QRS duration was $150 \pm 24 \mathrm{~ms}$ (Table 1).

\section{CMR and Catheterization Findings}

All patients showed significant volume overload, with a mean pulmonary regurgitation (PR) fraction of $35.4 \%$ $\pm 14.3 \%$ and a mean indexed PR volume of $22.1 \pm 11.1$ $\mathrm{mL} / \mathrm{m}^{2}$, which resulted in RV dilatation with a mean indexed end-diastolic volume of $125.9 \pm 29.5 \mathrm{~mL} / \mathrm{m}^{2}$ and a mean indexed end-systolic volume of $66.0 \pm 21.2$ $\mathrm{mL} / \mathrm{m}^{2}$. The mean $\mathrm{RV}$ ejection fraction was $48.3 \% \pm$ $8.8 \%$, and the RV indexed stroke volume was $59.9 \pm 16.6$ $\mathrm{ml} / \mathrm{m}^{2}$ (Table 1).

The hemodynamic data measured at each state are presented in Table 2. With dobutamine, the RV end-systolic volume decreased significantly (from $79.4 \pm 30.6$ to 64.2 $\pm 25.1 \mathrm{~mL} / \mathrm{m}^{2} ; P<.01$ ), which resulted in a greater $\mathrm{RV}$ stroke volume (from $72.8 \pm 34.6$ to $98.0 \pm 54.6 \mathrm{~mL} / \mathrm{m}^{2}$; $P<.01$ ) and ejection fraction (from $47.7 \% \pm 13.2 \%$ to $58.7 \% \pm 13.9 \% ; P<.01)$ in the presence of an unchanged
$\mathrm{RV}$ end-diastolic volume (from $152.8 \pm 45.6$ to $162.9 \pm$ $56.2 ; P=.20$ ). The RV end-systolic and end-diastolic pressure increased significantly. The pulmonary $\mathrm{Ea}$ (from 0.50 \pm 0.28 to $\left.0.72 \pm 0.48 \mathrm{~mm} \mathrm{Hg} / \mathrm{mL} / \mathrm{m}^{2} ; P<.01\right)$ and $\mathrm{RV}$ Ees (from $0.24 \pm 0.18$ to $0.47 \pm 0.39 \mathrm{~mm} \mathrm{Hg} / \mathrm{mL} / \mathrm{m}^{2}$; $P<.01)$ increased significantly under inotropic stimulation. RV-PA coupling was impaired at rest in the entire cohort and was nearly unchanged with dobutamine (Ea/Ees ratio from $2.99 \pm 2.77$ to $2.74 \pm 3.08 ; P=.70$ ).

The Ea showed a significant inverse relationship with the CMR-derived RV ejection fraction $(\mathrm{r}=-0.56 ; P=.02)$ and with the indexed PR volume $(\mathrm{r}=-0.77 ; P<.01$; Figure 2$)$. The Ea was not related to the RV diastolic function assessed as the end-diastolic pressure-volume relation $(r=0.21$; $P=.31$ ). The brain natriuretic peptide levels showed only a weak correlation with the $\mathrm{Ea}(\mathrm{r}=0.39 ; P=.06)$.

\section{Effect of Surgical Strategy}

To evaluate whether the surgical strategy at the primary repair affects the Ea and RV-PA coupling, we compared the 11 patients who had undergone TAP implantation with the 6 patients who had undergone a transatrial/transpulmonary approach. The transatrial/transpulmonary approach consisted of transtricuspid closure of the ventricular septal defect and a transpulmonary approach, including resection of the obstructing muscle bundles in the RVOT, with valvulotomy in 2 and partial valvectomy in 4 patients. No patches were inserted in the RVOT or supravalvular region.

Because the surgical strategy has changed in our center within the past 2 decades, the patients in the TAP group were significantly older than those in the transatrial/transpulmonary group $(18.6 \pm 6.3$ vs $10.4 \pm 0.8$ years; $P<.01)$. However, patient age at repair did not differ significantly between the 2 groups ( $2.2 \pm 1.7$ vs $0.9 \pm 0.4$ years; $P=.21)$. Four patients in the TAP group (36\%) and none in the transatrial/transpulmonary group were treated with palliative shunt procedures before corrective surgery $(P=.24)$. 
TABLE 1. Patient characteristics and CMR findings of study population

\begin{tabular}{|c|c|}
\hline Variable & Value \\
\hline \multicolumn{2}{|l|}{ Clinical data } \\
\hline Patients (n) & 24 \\
\hline \multicolumn{2}{|l|}{ Gender } \\
\hline Male & 15 \\
\hline Female & 9 \\
\hline Height $(\mathrm{cm})$ & $156 \pm 16$ \\
\hline Weight $(\mathrm{kg})$ & $53 \pm 25$ \\
\hline $\operatorname{BSA}\left(\mathrm{m}^{2}\right)$ & $1.49 \pm 0.38$ \\
\hline Age at study (y) & $16.7 \pm 7.0$ \\
\hline Age at repair (y) & $2.3 \pm 3.8$ \\
\hline Follow-up (y) & $14.4 \pm 4.9$ \\
\hline Palliative procedures (n) & $6(25)$ \\
\hline WCS (n) & $4(17)$ \\
\hline BTS (n) & $2(8)$ \\
\hline Age at palliative procedure $(\mathrm{y})$ & $0.8 \pm 1.0$ \\
\hline \multicolumn{2}{|l|}{ RVOT surgery type (n) } \\
\hline TAP & $11(46)$ \\
\hline RVOT patch & $4(16)$ \\
\hline Transatrial/transpulmonary & $6(25)$ \\
\hline RV-PA conduit & $3(13)$ \\
\hline \multicolumn{2}{|l|}{ NYHA class (n) } \\
\hline I & 21 \\
\hline II & 3 \\
\hline III & 0 \\
\hline QRS duration (ms) & $150 \pm 24$ \\
\hline $\mathrm{BNP}(\mathrm{pg} / \mathrm{mL})$ & $32.3 \pm 22.6$ \\
\hline RVOT gradient (mm Hg) & $8.0 \pm 8.2$ \\
\hline PVRi $\left(\mathrm{WU} / \mathrm{m}^{2}\right)$ & $1.98 \pm 1.08$ \\
\hline \multicolumn{2}{|l|}{ MRI data } \\
\hline RVEDVi (mL/m²) & $125.9 \pm 29.5$ \\
\hline $\operatorname{RVESVi}\left(\mathrm{mL} / \mathrm{m}^{2}\right)$ & $66.0 \pm 21.2$ \\
\hline $\operatorname{RVSVi}\left(\mathrm{mL} / \mathrm{m}^{2}\right)$ & $59.9 \pm 16.6$ \\
\hline $\operatorname{RVEF}(\%)$ & $48.3 \pm 8.8$ \\
\hline $\operatorname{PRF}(\%)$ & $35.4 \pm 14.3$ \\
\hline $\operatorname{PRVi}\left(\mathrm{mL} / \mathrm{m}^{2}\right)$ & $22.1 \pm 11.1$ \\
\hline LVEDVi $\left(\mathrm{mL} / \mathrm{m}^{2}\right)$ & $72.3 \pm 17.5$ \\
\hline LVESVi $\left(\mathrm{mL} / \mathrm{m}^{2}\right)$ & $29.3 \pm 9.4$ \\
\hline LVSVi $\left(\mathrm{mL} / \mathrm{m}^{2}\right)$ & $42.3 \pm 11.5$ \\
\hline $\operatorname{LVEF}(\%)$ & $58.7 \pm 7.7$ \\
\hline
\end{tabular}

BSA, Body surface area; WCS, Waterston-Cooley shunt; $B T S$, Blalock-Taussig shunt; $R V O T$, right ventricular outflow tract; $T A P$, transannular patch; $R V-P A$, right ventricle to pulmonary artery; $B N P$, brain natriuretic peptide; $i$, indexed for BSA; $R V$, right ventricular; $L V$, left ventricular; $E D V$, end-diastolic volume; $E S V$, end-systolic volume; $S V$, stroke volume; $E F$, ejection fraction; $P R F$, pulmonary regurgitant fraction; $P R V$, pulmonary regurgitant volume.

No difference was found in the frequency of clinical symptoms, brain natriuretic peptide levels $(32 \pm 21 \mathrm{pg} / \mathrm{mL}$ vs $23 /$ $11 \mathrm{pg} / \mathrm{mL}, P=.61)$, or QRS duration $(150 \pm 27 \mathrm{~ms}$ vs 145 $\pm 26 \mathrm{~ms} ; P=.76$ ) between the 2 groups. The magnetic resonance imaging parameters (PR fraction, $36.4 \% \pm 11.5 \%$ vs $35.3 \% \pm 8.0 \% ; P=.65$; and $\mathrm{RV}$ end-diastolic volume index $134.4 \pm 28.7 \mathrm{~mL} / \mathrm{m}^{2}$ vs $119.5 \pm 29.8 \mathrm{~mL} / \mathrm{m}^{2}$; $P=.37)$ and baseline catheterization measurements were comparable between the 2 groups. With dobutamine,
TABLE 2. Hemodynamic measures and indexes of right ventricular systolic and diastolic function

\begin{tabular}{|c|c|c|c|}
\hline Variable & Baseline & Dobutamine & $P$ value \\
\hline Heart rate (beats/min) & $56.5 \pm 7.8$ & $79.5 \pm 17.4$ & $<.01$ \\
\hline $\mathrm{CI}\left(\mathrm{L} / \mathrm{min} / \mathrm{m}^{2}\right)$ & $2.65 \pm 0.41$ & $4.19 \pm 0.7$ & $<.01$ \\
\hline End-systolic pressure $(\mathrm{mm} \mathrm{Hg})$ & $29.6 \pm 9.4$ & $55.9 \pm 24.5$ & $<.01$ \\
\hline End-diastolic pressure $(\mathrm{mm} \mathrm{Hg})$ & $9.2 \pm 6.1$ & $12.6 \pm 5.2$ & $<.01$ \\
\hline $\operatorname{RVEDVi}\left(\mathrm{mL} / \mathrm{m}^{2}\right)$ & $152.8 \pm 45.6$ & $162.9 \pm 56.2$ & .20 \\
\hline $\operatorname{RVESVi}\left(\mathrm{mL} / \mathrm{m}^{2}\right)$ & $79.4 \pm 30.6$ & $64.2 \pm 25.1$ & $<.01$ \\
\hline $\operatorname{RVSVi~}\left(\mathrm{mL} / \mathrm{m}^{2}\right)$ & $72.8 \pm 34.6$ & $98.0 \pm 54.6$ & $<.01$ \\
\hline $\operatorname{RVEF}(\%)$ & $47.7 \pm 13.2$ & $58.7 \pm 13.9$ & $<.01$ \\
\hline $\operatorname{PRF}(\%)$ & $34.8 \pm 17.0$ & $28.2 \pm 16.7$ & .05 \\
\hline $\mathrm{dP} / \mathrm{dt} \max (\mathrm{mm} \mathrm{Hg} / \mathrm{s})$ & $233 \pm 17$ & $776 \pm 303$ & $<.01$ \\
\hline $\mathrm{dP} / \mathrm{dt} \min (\mathrm{mm} \mathrm{Hg} / \mathrm{s})$ & $-333 \pm 88$ & $-777 \pm 228$ & $<.01$ \\
\hline $\operatorname{EDPVR}\left(\mathrm{mm} \mathrm{Hg} / \mathrm{mL} / \mathrm{m}^{2}\right)$ & $0.09 \pm 0.10$ & $0.14 \pm 0.15$ & .04 \\
\hline Tau (ms) & $51.1 \pm 26.1$ & $33.6 \pm 12.9$ & $<.01$ \\
\hline $\mathrm{Ea}\left(\mathrm{mm} \mathrm{Hg} / \mathrm{mL} / \mathrm{m}^{2}\right)$ & $0.50 \pm 0.28$ & $0.72 \pm 0.48$ & $<.01$ \\
\hline Ees $\left(\mathrm{mm} \mathrm{Hg} / \mathrm{mL} / \mathrm{m}^{2}\right)$ & $0.24 \pm 0.18$ & $0.47 \pm 0.39$ & $<.01$ \\
\hline $\mathrm{Ea} / \mathrm{Ees}$ & $2.99 \pm 2.77$ & $2.74 \pm 3.08$ & .70 \\
\hline
\end{tabular}

$C I$, Cardiac index; $R V$, right ventricular; $L V$, left ventricular; $E D V$, end-diastolic volume; $E S V$, end-systolic volume; $i$, indexed to body surface area; $S V$, stroke volume; $E F$, ejection fraction; $P R F$, pulmonary regurgitant fraction; $d P / d t$ max/min, maximal and minimal rate of pressure change in the ventricle; $E D P V R$, end-diastolic pressure volume relation; $E a$, pulmonary arterial elastance; Ees, ventricular end-systolic elastance; Ea/Ees, ventricular-arterial coupling.

a marked increase in the Ees (from $0.35 \pm 0.25$ to $0.83 \pm$ $\left.0.58 \mathrm{~mm} \mathrm{Hg} / \mathrm{mL} / \mathrm{m}^{2} ; P=.06\right)$ in conjunction with a slight increase in Ea (from $0.42 \pm 0.25$ to $0.55 \pm 0.3 \mathrm{~mm} \mathrm{Hg} / \mathrm{mL} /$ $\mathrm{m}^{2} ; P=.08$ ) was observed in the transatrial/transpulmonary group. In contrast, the Ees increased only marginally in the TAP group (from $0.26 \pm 0.16$ to $0.40 \pm 0.24 \mathrm{~mm} \mathrm{Hg} / \mathrm{mL} /$ $\left.\mathrm{m}^{2} ; P=.12\right)$ combined with a marked increase in the Ea (from $0.50 \pm 0.26$ to $0.78 \pm 0.52 \mathrm{~mm} \mathrm{Hg} / \mathrm{mL} / \mathrm{m}^{2}$; $P=.008)$. This resulted in a significant and contrary change in RV-PA coupling in the 2 groups. Although in the TAP group, the Ea/Ees ratio worsened from $2.01 \pm 0.84$ to $3.70 \pm 4.11(P=.20)$, it improved in the transatrial group from $1.61 \pm 1.0$ to $0.88 \pm 0.64(P=.10)$, illustrating significant uncoupling in the TAP group, at rest and even more pronounced in response to dobutamine $(P=.04$, compared with the transatrial/transpulmonary group; Figure 3). Although the 2 compared groups differed significantly in the duration of follow-up since repair, this factor showed no relationship with Ea, Ees, or Ea/Ees, excluding that age was a confounding factor for the observed differences in the 2 groups.

\section{DISCUSSION}

Our study has demonstrated that in patients late after repair of TOF, RV-PA coupling is impaired, reflecting a maladaptive response of the PA system to chronic volume overload in the presence of preserved RV contractility. Furthermore, despite a significant increase in RV contractility under inotropic stimulation, dobutamine was not able to 

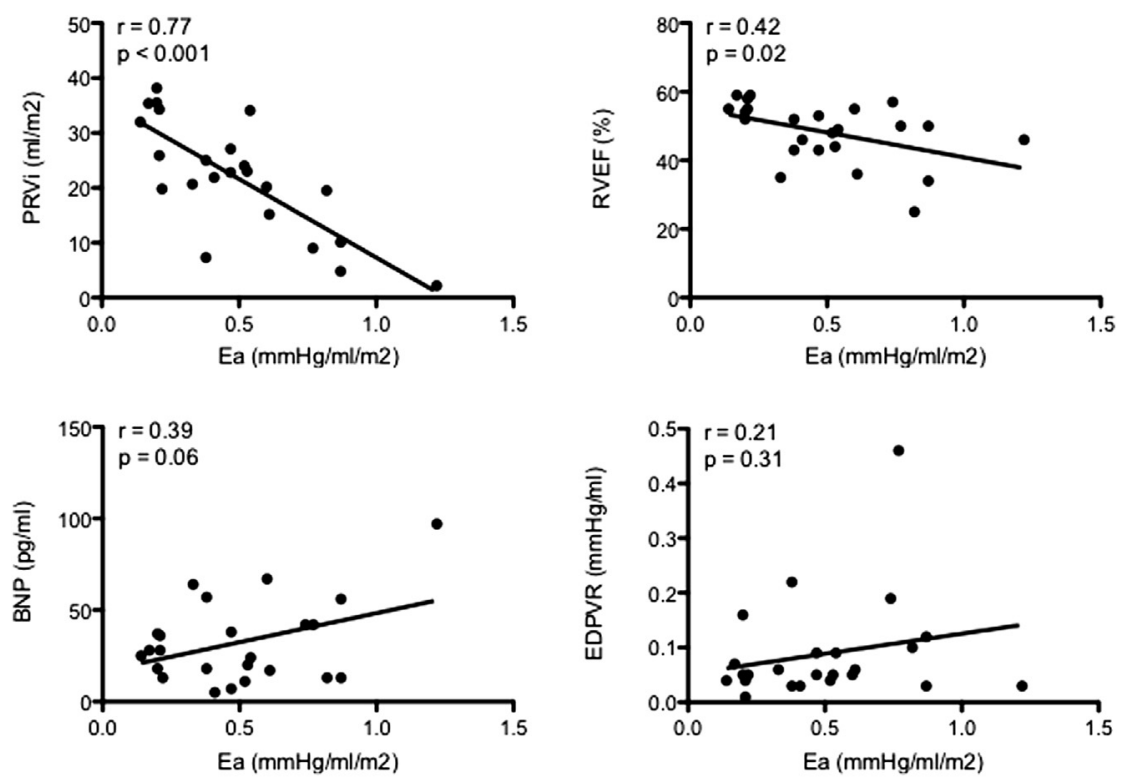

FIGURE 2. Relationship between pulmonary arterial elastance $(E a)$ and indexed pulmonary regurgitant volume (PRVi), right ventricular ejection fraction $(R V E F)$ and brain natriuretic peptide $(B N P)$ levels. The arterial elastance $(E a)$ showed no correlation with the RV end-diastolic volume relation $(E D P V R)$ as a parameter of the RV intrinsic diastolic function.

restore RV-PA coupling by a simultaneous increase in pulmonary Ea. In addition, we were able to show that the surgical technique used at the primary repair has a major effect on the ventricular-vascular interactions, with patients who received a TAP having significant worse coupling than patients with transatrial TOF repair.

Several previous studies have evaluated the mechanisms for deterioration in RV performance in patients after TOF repair. These studies mainly focused on the RV dimensions and function; however, RV-PA coupling has never previously been assessed systematically in these patients. In our entire study population, ventricular Ees was lower than $\mathrm{Ea}$, a condition remote from the point at which stroke work or mechanical efficiency is optimal. ${ }^{8}$ Inotropic stimulation with dobutamine caused a significant increase of both $\mathrm{Ea}$ and Ees, with a mild, but not significant, decrease in the
$\mathrm{Ea} /$ Ees ratio and, therefore, resulted in nearly unchanged RV-PA coupling. These findings imply that inotropic stimulation in patients with TOF does not result in improved adaptation of the vascular properties, despite an appropriate increase in the Ees. This was confirmed by data from an experimental swine model with severe PR, in which dobutamine resulted in an increase in the $\mathrm{Ea} / \mathrm{Ees}$ ratio, indicating worsened coupling. ${ }^{15}$

When longstanding severe PR is present after TOF repair, the absolute stroke volume is increased to maintain sufficient cardiac output. This situation results in subsequent chronic volume overload of both the right ventricle and the proximal PA system. Over time, a progressive increase in the size and capacitance of the central pulmonary arteries is frequently observed in patients with TOF late after repair. In healthy humans with a competent valve, arterial
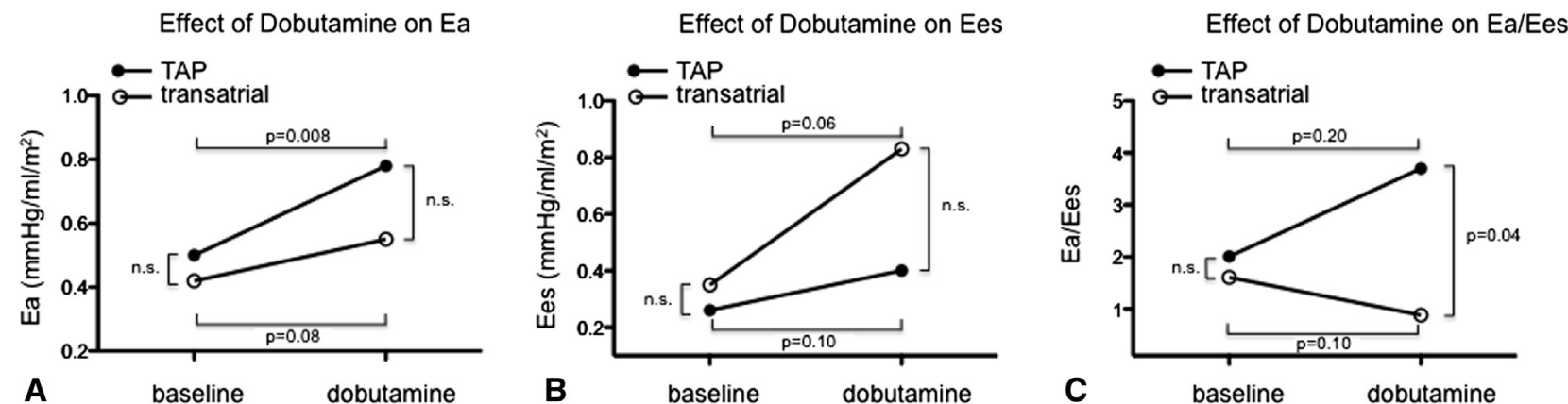

FIGURE 3. Changes in response to dobutamine (mean values) of effective (A) pulmonary arterial elastance (Ea), (B) right ventricular end-systolic elastance $(E e s)$, and $(\mathrm{C})$ right ventricular-pulmonary arterial $(R V-P A)$ coupling Ea/Ees ratio in patients with transannular patch repair $(T A P)$ and in patients who underwent a transatrial/transpulmonary approach. Note the significant difference in RV-PA coupling in response to dobutamine between the 2 groups. 
compliance of the large vessels is considered beneficial because it helps to reduce RV pulsatile afterload. The situation in patients with TOF is more complex, because a highly compliant PA system reduces RV afterload but simultaneously exacerbates PR in the absence of a functional pulmonary valve owing to the elastic recoil of the pulmonary arteries in early diastole. ${ }^{16}$ When the pulmonary arteries lose their elasticity, which probably depends on their native size and histologic structure, this results in a subsequent increase in stiffness and RV pulsatile afterload. ${ }^{17}$ Accordingly, one might suspect whether some form of vascular adaptation of the pulmonary arteries occurs to the chronic volume overload to maintain an optimal coupling between the right ventricle and vascular system.

Recently, an abnormal elastic tissue configuration in the pulmonary trunks of patients with TOF and an increased extent of medionecrosis and fibrosis has been reported that might affect mechanical wall properties. ${ }^{18}$ Supporting the important role of the central pulmonary arteries, a study using 4-dimensional CMR velocity mapping showed increased wall shear stress in the main pulmonary trunk of patients with TOF. ${ }^{19}$ Considering the previously described histologic abnormalities of the aorta that also affect left ventricular function in patients with $\mathrm{TOF}^{20,21}$ it might be possible that similar histopathologic alterations in pulmonary trunk composition could contribute to alterations in its mechanical properties, with a subsequent influence on RV performance and PR. A corresponding study conducted of patients with aortic regurgitation showed that vascular maladaption might result in additional load on the left ventricle with a deterioration in left ventricular performance. ${ }^{22}$

The stroke volume/end-systolic pressure ratio, known as the effective Ea, represents a valid estimate of pulsatile afterload in the systemic circulation and in the PA system. ${ }^{5,6}$ This parameter incorporates all elements of vascular load, including PA compliance, which is considered necessary for adequate ventriculoarterial coupling. ${ }^{7,23}$ Because Ea is mainly influenced by PR, these parameters show significant inverse correlation. We also found a significant inverse relationship between the Ea and RV ejection fraction, indicating that RV function is not only influenced by the amount of volume overload but also directly affected by the pulsatile afterload. This finding demonstrates that only assessing PR might not reflect the total hemodynamic burden of the right ventricle in patients with TOF late after repair. The Ea showed no correlation with the end-diastolic pressure-volume relation, indicating that diastolic RV function, including restrictive physiology, is not related to afterload and primarily reflects a myocardial issue.

Depending on the size of the pulmonary annulus and PA system, the surgical therapy includes a transatrial/transpulmonary approach or a traditionally performed TOF repair by ventriculotomy, commonly combined with implantation of a TAP ${ }^{24-27}$ The latter procedure implies extension of the longitudinal incision across the ventriculoarterial junction into the right ventricle and augmentation of the RVOT with a patch. The observed RV-PA uncoupling in the transannular patch group under inotropic stimulation was the result of a marked increase in Ea and a blunted increase in Ees compared with the transatrial repair group. These findings are indicative of a maladaptive vascular response to an increased stroke volume, with a subsequent increase in RV pulsatile afterload, and might reflect that the noncontractile patch material implanted over the RV-PA conjunction directly affects both ventricular performance and pulmonary vascular properties. ${ }^{27}$

\section{Study Limitations}

Our study population was small, and, in particular, the subgroup analysis included only 17 patients who differed significantly in terms of age and also in the duration of follow-up. Although we were able to exclude this as a confounding factor in our study, the effect of aging on the Ea, Ees, and Ea/Ees remains unknown.

The present study was mainly designed to perform a physiologic analysis to reveal causes of maladaptation after repair of TOF and to compare the sequelae of different surgical approaches. We can only speculate on the reasons and mechanisms by which they have occurred and their implications for the patients' clinical condition and outcomes. Additional studies are necessary to evaluate the effect of Ea, Ees, and $\mathrm{Ea} / \mathrm{Ees}$ on exercise and outcome.

\section{CONCLUSIONS}

By evaluation of the ventricular-arterial coupling, the results of our study provide new insights into the RV response to chronic volume overload and might help in finding additional mechanisms for the deterioration of RV performance and the response to therapeutic interventions in the longterm follow-up of patients with repaired TOF. Our study has demonstrated that unfavorable RV-PA coupling is present in patients with TOF and is affected by the surgical strategy used at primary repair. These results elucidate the emerging role of ventricular-arterial interactions as a contributing mechanism for the observed decline in RV function and impaired response to inotropic drugs in patients with TOF.

\section{References}

1. Geva T, Sandweiss BM, Gauvreau K, Lock JE, Powell AJ. Factors associated with impaired clinical status in long-term survivors of tetralogy of Fallot repair evaluated by magnetic resonance imaging. J Am Coll Cardiol. 2004;43:1068-74.

2. Gatzoulis MA, Balaji S, Webber SA, Siu SC, Hokanson JS, Poile C, et al. Risk factors for arrhythmia and sudden cardiac death late after repair of tetralogy of Fallot: a multicentre study. Lancet. 2000;356:975-81.

3. Gatzoulis MA, Till JA, Somerville J, Redington AN. Mechanoelectrical interaction in tetralogy of Fallot: QRS prolongation relates to right ventricular size and 
predicts malignant ventricular arrhythmias and sudden death. Circulation. 1995; 92:231-7.

4. Sunagawa K, Maughan WL, Burkhoff D, Sagawa K. Left ventricular interaction with arterial load studied in isolated canine ventricle. Am J Physiol. 1983; 245(5 Pt 1):H773-80.

5. Kelly RP, Ting CT, Yang TM, Liu CP, Maughan WL, Chang MS, et al. Effective arterial elastance as index of arterial vascular load in humans. Circulation. 1992; 86:513-21.

6. Morimont P, Lambermont B, Ghuysen A, Gerard P, Kolh P, Lancellotti P, et al. Effective arterial elastance as an index of pulmonary vascular load. Am J Physiol Heart Circ Physiol. 2008;294:H2736-42.

7. Fourie PR, Coetzee AR, Bolliger CT. Pulmonary artery compliance: its role in right ventricular-arterial coupling. Cardiovasc Res. 1992;26:839-44.

8. Burkhoff D, Sagawa K. Ventricular efficiency predicted by an analytical model. Am J Physiol. 1986;250(6 Pt 2):R1021-7.

9. Kuehne T, Yilmaz S, Steendijk P, Moore P, Groenink M, Saaed M, et al. Magnetic resonance imaging analysis of right ventricular pressure-volume loops: in vivo validation and clinical application in patients with pulmonary hypertension. Circulation. 2004;110:2010-6.

10. Sanz J, Garcia-Alvarez A, Fernandez-Friera L, Nair A, Mirelis JG, Sawit ST, et al. Right ventriculoarterial coupling in pulmonary hypertension: a magnetic resonance study. Heart. 2012;98:238-43.

11. Apitz C, Latus H, Binder W, Uebing A, Seeger A, Bretschneider C, et al. Impact of restrictive physiology on intrinsic diastolic right ventricular function and lusitropy in children and adolescents after repair of tetralogy of Fallot. Heart. 2010; 96:1837-41.

12. Derrick GP, Narang I, White PA, Kelleher A, Bush A, Penny DJ, et al. Failure of stroke volume augmentation during exercise and dobutamine stress is unrelated to load-independent indexes of right ventricular performance after the Mustard operation. Circulation. 2000;102(19 Suppl 3):III154-9.

13. Tanoue Y, Sese A, Imoto Y, Joh K. Ventricular mechanics in the bidirectional Glenn procedure and total cavopulmonary connection. Ann Thorac Surg. 2003; 76:562-6.

14. Schlangen J, Fischer G, Steendijk P, Petko C, Scheewe J, Hart C, et al. Does left ventricular size impact on intrinsic right ventricular function in hypoplastic left heart syndrome? Int J Cardiol Epub. 2012 Apr 23.

15. Kuehne T, Saeed M, Gleason K, Turner D, Teitel D, Higgins CB, et al. Effects of pulmonary insufficiency on biventricular function in the developing heart of growing swine. Circulation. 2003;108:2007-13.
16. Kilner PJ, Balossino R, Dubini G, Babu-Narayan SV, Taylor AM, Pennati G, et al. Pulmonary regurgitation: the effects of varying pulmonary artery compliance, and of increased resistance proximal or distal to the compliance. Int J Cardiol. 2009; 133:157-66.

17. Geva T. Repaired tetralogy of Fallot: the roles of cardiovascular magnetic resonance in evaluating pathophysiology and for pulmonary valve replacement decision support. J Cardiovasc Magn Reson. 2011;13:9.

18. Bedard E, McCarthy KP, Dimopoulos K, Giannakoulas G, Gatzoulis MA, Ho SY. Structural abnormalities of the pulmonary trunk in tetralogy of Fallot and potential clinical implications: a morphological study. J Am Coll Cardiol. 2009;54: 1883-90.

19. Francois CJ, Srinivasan S, Schiebler ML, Reeder SB, Niespodzany E, Landgraf BR, et al. 4D cardiovascular magnetic resonance velocity mapping of alterations of right heart flow patterns and main pulmonary artery hemodynamics in tetralogy of Fallot. J Cardiovasc Magn Reson. 2012;14:16.

20. Grotenhuis HB, Ottenkamp J, de Bruijn L, Westenberg JJ, Vliegen HW, Kroft LJ, et al. Aortic elasticity and size are associated with aortic regurgitation and left ventricular dysfunction in tetralogy of Fallot after pulmonary valve replacement. Heart. 2009;95:1931-6.

21. Senzaki H, Iwamoto Y, Ishido H, Matsunaga T, Taketazu M, Kobayashi T, et al. Arterial haemodynamics in patients after repair of tetralogy of Fallot: influence on left ventricular after load and aortic dilatation. Heart. 2008;94:70-4.

22. Devlin WH, Petrusha J, Briesmiester K, Montgomery D, Starling MR. Impact of vascular adaptation to chronic aortic regurgitation on left ventricular performance. Circulation. 1999;99:1027-33.

23. Piene H, Sund T. Flow and power output of right ventricle facing load with variable input impedance. Am J Physiol. 1979;237:H125-30.

24. Castaneda AR. Classical repair of tetralogy of Fallot: timing, technique, and results. Semin Thorac Cardiovasc Surg. 1990;2:70-5.

25. del Nido PJ. Surgical management of right ventricular dysfunction late after repair of tetralogy of Fallot: right ventricular remodeling surgery. Semin Thorac Cardiovasc Surg. 2006;29-34.

26. Uebing A, Fischer G, Bethge M, Scheewe J, Schmiel F, Stieh J, et al. Influence of the pulmonary annulus diameter on pulmonary regurgitation and right ventricular pressure load after repair of tetralogy of Fallot. Heart. 2002;88:510-4.

27. Bove T, Bouchez S, De Hert S, Wouters P, De Somer F, Devos D, et al. Acute and chronic effects of dysfunction of right ventricular outflow tract components on right ventricular performance in a porcine model: implications for primary repair of tetralogy of Fallot. J Am Coll Cardiol. 2012;60:64-71. 